\title{
The effects of different concentrations of glucose on glucose sensors and GLP-1 secretion in the enteroendocrine cell line STC-1
}

\author{
Fei Huang ${ }^{1, *}$, Lurong Zhang ${ }^{2,3, *}$, Xiudao Song ${ }^{2,3}$, Heng Xu ${ }^{2,3}$, Fei Wang ${ }^{2,3}$, Liang Zhou ${ }^{2,3}$, \\ Guoqiang Liang ${ }^{2,3}$ and Guorong Jiang ${ }^{2,3}$ \\ ${ }^{1}$ Department of Endocrinology, Suzhou TCM Hospital Affiliated to Nanjing University of Chinese Medicine, Suzhou, Jiangsu, China \\ ${ }^{2}$ Clinical Pharmaceutical Laboratory of Traditional Chinese Medicine, Suzhou TCM Hospital Affiliated to Nanjing University \\ of Chinese Medicine, Suzhou, Jiangsu, China \\ ${ }^{3}$ Clinical Pharmaceutical Laboratory of Traditional Chinese Medicine, Suzhou Academy of Wumen Chinese Medicine, \\ Suzhou, Jiangsu, China
}

\begin{abstract}
Glucose triggers glucagon-like peptide (GLP)-1 secretion from L cells involving several glucose sensors including sodium-glucose transporter (SGLT)1, glucose transporter (GLUT)2, and sweet taste receptors (STRs). This study investigated the effects of different glucose concentrations on GLP-1 secretion, intracellular concentrations of $\mathrm{Ca}^{2+}$ and cAMP, glucose uptake, and protein levels of SGLT1, GLUT2, and STRs in STC-1 cells. Low glucose (5.6 mM) increased GLP-1 secretion, intracellular $\mathrm{Ca}^{2+}$ concentration, and SGLT1 protein level compared with glucose-free group. GLP-1 secretion and intracellular $\mathrm{Ca}^{2+}$ concentration triggered by low glucose were inhibited by the SGLT1 inhibitor. GLP-1 secretion or intracellular $\mathrm{Ca}^{2+}$ concentration in high-glucose $(25,100$, $200 \mathrm{mM}$ ) groups was significantly higher than that of low-glucose group. Elevation of cAMP level was observed in concentration-dependent manner, and decreased glucose uptake was observed in 100 or $200 \mathrm{mM}$ glucose group. High glucose increased protein levels of STRs and GLUT2 in comparison to low-glucose group. GLP-1 secretion and intracellular levels of $\mathrm{Ca}^{2+}$ and cAMP triggered by high glucose were inhibited in the presence of the GLUT2 or STR inhibitor. These results suggest that SGLT1 is dominantly responsible for GLP-1 secretion triggered by low glucose, and that STRs and GLUT2 are involved in GLP-1 secretion induced by high glucose.
\end{abstract}

Key words: Glucose-induced GLP-1 secretion - Sodium-glucose transporter 1 - Glucose transporter 2 - Sweet taste receptor

\section{Introduction}

Oral intake of nutrients results in the secretion of gut incretin hormones including glucagon-like peptide (GLP)-1 and glucose-dependent insulinotropic polypeptide (GIP). GLP-1 and GIP together account for 50-70\% of prandial insulin secretion (Shuster et al. 2017). In terms of the treatment of type 2 diabetes mellitus (T2DM), GLP-1 is being a special interest

\footnotetext{
* These authors contributed equally.

Crrespondence to: Guorong Jiang, Clinical Pharmaceutical Laboratory of Traditional Chinese Medicine, Suzhou TCM Hospital Affiliated to Nanjing University of Chinese Medicine, No. 18, Yangsu Road, Suzhou 215009, Jiangsu, China

E-mail: szguorongjiang@163.com
}

for its broad role in glucose homeostasis. GLP-1 postprandially secreted by intestinal enteroendocrine L-cells potentiates glucose-induced insulin release from pancreatic beta-cells (Doyle and Egan 2007). Glucose-lowering effect of GLP-1 also exerts via increasing insulin-independent glucose disposal, for example, reducing glucagon secretion, inhibiting the appetite, and delaying gastric emptying (Holst 2007). GLP-1-based agents, namely stable GLP-1 analogs and dipeptidyl peptidase 4 inhibitors, are used for T2DM therapy (Drucker and Nauck 2006; Kim and Egan 2008). Additionally, there is now generally accepted that the metabolic benefits of the Roux-en-Y gastric bypass and vertical sleeve gastrectomy are partly attributable to the postprandially increased GLP-1 level (Benaiges et al. 2011). These new therapeutic strategies highlight the importance of endogenous GLP-1 in maintaining glucose homeostasis. 
As glucose is the most important energy source and its ambient level needs to be maintained, many cell types, including pancreatic beta-cells and enteroendocrine L-cells, are equipped with a glucose-sensing apparatus. Accumulating evidence indicated that luminal glucose exposure potently stimulates GLP-1 secretion from isolated perfused rat or human small intestine (Kuhre et al. 2015; Xu et al. 2016; Sun et al. 2017). From studies of the GLP-1-expressing cell lines (Gribble et al. 2003; Parker et al. 2012) including STC-1, GLUTag and NCI-H716, primary murine intestinal mixed cell cultures (Frank et al. 2008), in vivo transgenic mouse models (Cani et al. 2007; Gorboulev et al. 2012), an ex vivo rat model (Kuhre et al. 2015), and an ex vivo human model (Sun et al. 2017), several glucose sensors have suggested to link glucose exposure to GLP-1 secretion. They include electrogenic glucose transport sodium-glucose transporter (SGLT)1 and facilitative glucose transporter (GLUT)2. It has been proposed that glucose induces GLP-1 release through SGLT1, and to a lesser extent, GLUT2. Studies also indicated that sweet taste receptors (STRs, TAS1R2-TAS1R3) signaling is also involved in glucose-induced GLP-1 release (Jang et al. 2007; Kokrashvili et al. 2009; Xu et al. 2016).

After a meal, although the exact concentration of luminal glucose is the big unknown, it estimates range from 50 to $300 \mathrm{mM}$ (Kellett and Brot-laroche 2006). In this study, using enteroendocrine STC-1 cells, we investigated the effect of luminal glucose concentration $(5.6,25,100$, and $200 \mathrm{mM}$ ) on GLP-1 secretion, intracellular concentrations of $\mathrm{Ca}^{2+}$ and CAMP, glucose uptake, and the protein expression levels of SGLT1, GLUT2, and STRs. The SGLT1, GLUT2 and STRs inhibitor were used as an intervention reagent to evaluate the role of SGLT1, GLUT2, and STRs in GLP-1 secretion triggered by different concentrations of glucose, respectively.

\section{Materials and Methods}

\section{Reagents}

Phloretin, lactisole, and phloridzin dihydrate purchased from Sigma-Aldrich (St. Louis, MO, USA) were prepared as a stock solution in DMSO. For all conditions tested, the final concentration of DMSO, phloretin, lactisole, and phloridzin dihydrate was adjusted to $0.05 \%, 0.1 \mathrm{mM}, 5 \mathrm{mM}$, and $0.5 \mathrm{mM}$, respectively.

\section{Cell culture}

STC-1 cells, a murine enteroendocrine intestinal cell line, were purchased from Cell Bank of the Chinese Academy of Sciences (Shanghai, China). The cells were maintained in Dulbecco's modified Eagle's medium (DMEM; Gibco;
Thermo Fisher Scientific, Inc., Waltham, MA, USA) with $25 \mathrm{mM}$ glucose supplemented with $10 \%$ fetal bovine serum (FBS; Zhejiang Tianhang Biological Technology Co., Ltd., Huzhou, China) and antibiotics (100 units/ml penicillin and $0.1 \mathrm{ng} / \mathrm{ml}$ streptomycin) at $37^{\circ} \mathrm{C}$ in a humidified atmosphere containing $5 \% \mathrm{CO}_{2}$. The cells were grown to $85 \%$ confluence for the experiments.

\section{Measurement of GLP-1 secretion}

STC- 1 cells were seeded into 24 -well plates at a density of $1.5 \times 10^{5}$ cells/well for $48 \mathrm{~h}$. The cells were washed with phosphate buffer saline (PBS) for three times, then incubated with glucose-free DMEM for $3 \mathrm{~h}$. The medium was subsequently removed, and the cells were treated with the indicated reagents for variable times (see figure legends). After the incubation, the medium was collected and centrifuged at $12000 \times g$ for $5 \mathrm{~min}$ at $4^{\circ} \mathrm{C}$. The GLP- 1 concentration (total) in the supernatant was measured using a GLP-1 Total ELISA kit (Millipore, MA, USA).

\section{Determination of intracellular $\mathrm{Ca}^{2+}$ levels}

STC- 1 cells were plated at a density of $1.5 \times 10^{5}$ cells/well in 6-well plates for $48 \mathrm{~h}$. The cells were washed with PBS for three times, then incubated with glucose-free DMEM for $3 \mathrm{~h}$. The cells were incubated with different concentrations of glucose in the presence and absence of various agents for variable times (see figure legends). $1 \mu \mathrm{l}$ Fluo-3/AM (Beyotime, Jiangsu, China) was added in each well at room temperature and then incubated for $30 \mathrm{~min}$. Then the cells were washed three times with PBS. Mean fluorescence ratios of the cells were determined by flow cytometry (BD Accuri C6, Ann Arbor, USA) with excitation/emission, 488/525-530, and analyzed by BD software 1.0.

\section{Determination of intracellular cAMP levels}

STC- 1 cells were seeded into 6-well plates at a density of $1.5 \times 10^{5}$ cells/well for $48 \mathrm{~h}$. The cells were washed three times with PBS. Then the cells were incubated with glucose-free DMEM for $3 \mathrm{~h}$. The cells were incubated with different concentrations of glucose in the presence and absence of various agents for variable times (see figure legends). After the incubation, cells were collected and cell lysates were prepared for the measurement of cAMP levels using an ELISA kit (Shanghai BangYi Bio-Technology Co., Ltd., Shanghai, China).

\section{Measurement of glucose uptake}

The glucose uptake was measured by using 2-[N-(7nitrobenz-2-oxa-1,3-diazol-4-yl) amino]-2-deoxyglucose (2-NBDG) (Cayman Chemical Co., Ann Arbor, MI, USA), 
as previously described (Wang et al. 2017). The STC-1 cells were plated in 96-well plate for $48 \mathrm{~h}$ and then washed with Krebs-Ringer bicarbonate (KRb) buffer (4A Biotech Co. Ltd., Beijing, China). Different concentration of glucose (at 0, 5.6, 25,100 , and $200 \mathrm{mM}$ ) was added into the medium. After $1-\mathrm{h}$ incubation, the cells were washed twice with KRb buffer. Then $100 \mu \mathrm{l}$ serum-free KRb buffer containing $160 \mu \mathrm{M} 2-\mathrm{NBDG}$ was added and continued to incubate for $30 \mathrm{~min}$ at $37^{\circ} \mathrm{C}$. The medium was subsequently removed, and the fluorescence intensity in the cells was measured using a fluorescence microplate reader (excitation/emission, 488/520; Model 680, Bio-Rad Laboratories, Inc., Hercules, CA, USA).

\section{Western blot analysis}

After treatment with glucose-free DMEM for $3 \mathrm{~h}, \mathrm{STC}-1$ cells were incubated with different concentrations of glucose $(0$, $5.6,25,100$, and $200 \mathrm{mM}$ ) for $1 \mathrm{~h}$. The cells were harvested, and cell lysates were prepared. BCA Protein Assay Kit (Beyotime, Jiangsu, China) was used to determine the protein content in the lysates. For Western blot analysis, 50-100 $\mu \mathrm{g}$ of protein from each sample was subjected to separate on a SDS-PAGE gel. The blots of proteins in polyvinylidene difluoride membranes (Merck Millipore, Darmstadt, Germany) were incubated with the appropriate primary antibody and incubated with horseradish peroxidase (HRP)-conjugated secondary antibody. The blots were detected with chemiluminescence (ECL-kit, Beyotime, Jiangsu, China) followed by autoradiography. The antibodies used for Western blot were as follows: anti-SGLT1 (Abcam, Cambridge, UK), anti-GLUT2 (Abcam, Cambridge, UK), anti-STR subunit TAS1R2 (Santa Cruz Biotechnology, Santa Cruz, CA), anti-STR subunit
TAS1R3 (Santa Cruz Biotechnology, Santa Cruz, CA), and anti- $\beta$-actin antibody (Santa Cruz Biotechnology, Santa Cruz, CA). Quantification of protein bands was performed using ImageJ software version 1.42 (National Institutes of Health, Bethesda, MD, USA).

\section{Statistical analysis}

All of the data shown are representative of at least three independent experiments performed in duplicates and are expressed as mean \pm SD. Statistical significance of differences was analyzed by the Student's $t$-test or analysis of variance followed by the Bonferroni or Dunnett's post hoc tests (Graph Pad Prism Software, San Diego, CA, USA). All $p$-values $\leq 0.05$ were considered statistically significant.

\section{Results}

Effects of different concentrations of glucose on GLP-1 secretion and intracellular $\mathrm{Ca}^{2+}$ level

As shown in Fig. 1A, exposure to glucose (at 5.6, 25, 100, and $200 \mathrm{mM}$ ) significantly stimulated GLP-1 secretion from STC- 1 cells compared with the glucose-free control group, with a maximum stimulation of $\sim 1.36$-fold. Compared with the group of $5.6 \mathrm{mM}$ glucose stimulation, GLP-1 secretion from STC-1 cells was significantly increased by approximately 1.15 -fold in the groups of high-glucose $(25,100$, and $200 \mathrm{mM}$ ) stimulation (Fig. 1A). There was not a significant difference in GLP-1 secretion among the groups of 25, 100, and $200 \mathrm{mM}$ glucose (Fig. 1A). We then examined the effect
A

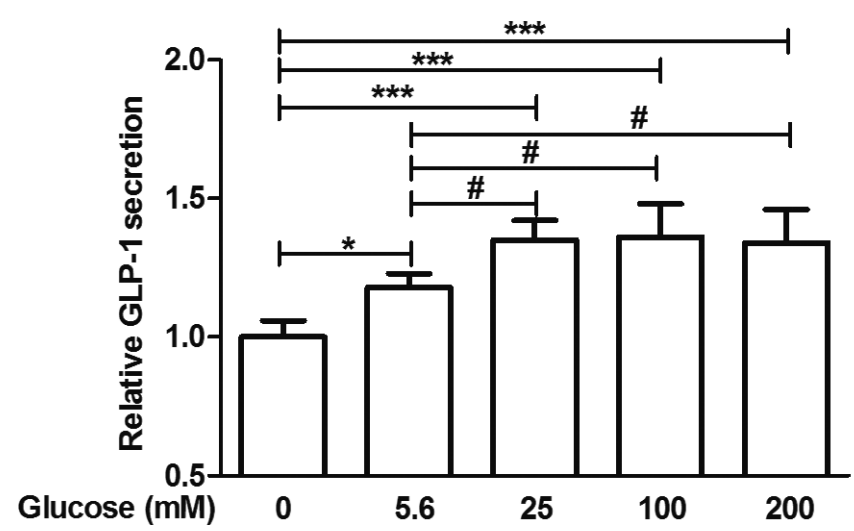

B

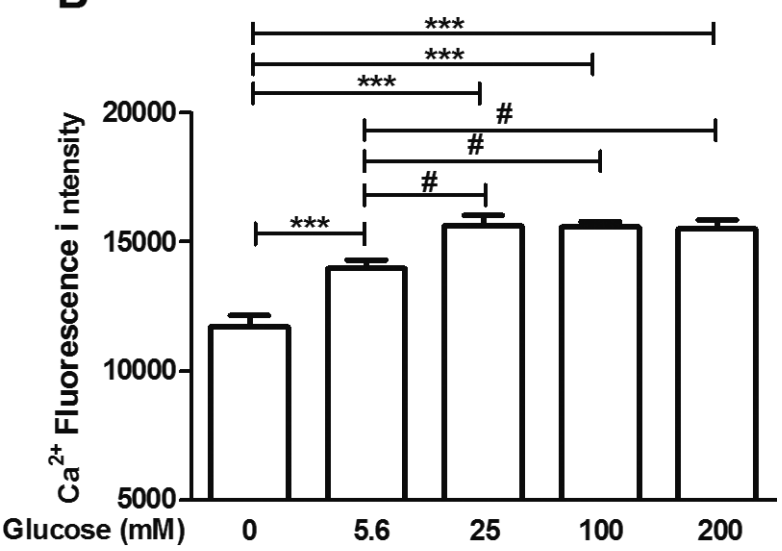

Figure 1. Effects of different concentrations of glucose on GLP-1 secretion and intracellular Ca ${ }^{2+}$ level in STC-1 cells. STC-1 cells were incubated with different concentrations of glucose $(0,5.6,25,100$, and $200 \mathrm{mM})$ for $1 \mathrm{~h}$. A. The GLP-1 concentration in the supernatant was measured by ELISA. All data were expressed as the relative dimensionless number of the glucose-free control group. ${ }^{*} p<0.05$, ${ }^{* * *} p<0.001,{ }^{\#} p<0.05(n=6)$. B. The $\mathrm{Ca}^{2+}$ concentrations in STC-1 cells were measured at the 488/525-530 nm fluorescence ratio in the cells loaded with fluo-3/AM. ${ }^{* *} p<0.001,{ }^{*} p<0.05(n=6)$. 
of different concentrations of glucose on intracellular $\mathrm{Ca}^{2+}$ concentration in STC-1 cells. As shown in Fig. 1B, the groups of 5.6, 25, 100, and $200 \mathrm{mM}$ glucose stimulation exhibited a significant increase in intracellular $\mathrm{Ca}^{2+}$ concentration compared with the glucose-free control group, with a maximum stimulation of approximately 1.34 -fold. Intracellular $\mathrm{Ca}^{2+}$ concentration in the group of $25 \mathrm{mM}$ glucose stimulation was dramatically higher than that of the 5.6 glucose group, but no significant difference in intracellular $\mathrm{Ca}^{2+}$ concentration was observed among the groups of 25, 100, and $200 \mathrm{mM}$ groups (Fig. 1B). In terms of GLP-1 secretion and intracellular $\mathrm{Ca}^{2+}$ concentration, glucose ranged from 5.6 to $200 \mathrm{mM}$ appeared to have a similar effect.

Effects of different concentrations of glucose on intracellular cAMP level and glucose uptake

The elevation of intracellular cAMP level was reported to increase GLP-1 secretion in several models of intestinal enteroendocrine cells, associated with the release of $\mathrm{Ca}^{2+}$ from intracellular stores (Simpson et al. 2007). Thus we further examined the effect of different concentrations of glucose on intracellular cAMP levels. As shown in Fig. 2A, compared with the glucose-free control group, glucose at $5.6 \mathrm{mM}$ concentration did not alter intracellular cAMP levels. Following treatment with 25, 100 and $200 \mathrm{mM}$ glucose, intracellular cAMP levels were markedly elevated to approximately 1.5 -fold, 3.5-fold, and 4.6-fold, respectively. Furthermore, glucose ranged from 5.6 to $200 \mathrm{mM}$ increased intracellular cAMP levels in a concentration-dependent manner (Fig. 2A). L-cell function depends on glucose uptake, and the subsequent signaling pathways influence the concentration of intracellular cAMP. Thus, we examined the effect of different concentrations of glucose on glucose uptake. 2-NBDG was used for the determination of glucose uptake. Compared with the glucose-free control group, no significant difference in 2-NBDG uptake was observed between $5.6 \mathrm{mM}$ glucose group and $25 \mathrm{mM}$ glucose group. 2-NBDG uptake was significantly attenuated by either 100 or $200 \mathrm{mM}$ glucose treatment (Fig. 2B), which reflects that the ability of cells to uptake glucose decreases after exposure to either 100 or $200 \mathrm{mM}$ glucose stimulation.

\section{Effects of different concentrations of glucose on the protein levels of SGLT1, GLUT2 and STR subunits}

To determine the involvement of SGLT1, GLUT2 or STRs in GLP-1 secretion induced by different concentrations of glucose, we treated STC-1 cells with different concentrations of glucose (at $0,5.6,25,100$, and $200 \mathrm{mM}$ ) for $1 \mathrm{~h}$ and compared the protein levels of SGLT1, GLUT2, and STRs. As shown in Fig. 3, SGLT1 expression gradually increased when glucose concentration in the medium was reduced from 100 to $5.6 \mathrm{mM}$. No significant difference in SGLT1 expression was observed between the group of $100 \mathrm{mM}$ glucose and the group of $200 \mathrm{mM}$ glucose. Importantly, $5.6 \mathrm{mM}$ glucose treatment induced a significant increase in SGLT1 protein level in comparison to the glucose-free control group (Fig. 3). By contrast, no significant difference in GLUT2 protein expression was observed between the $5.6 \mathrm{mM}$ glucose group and glucose-free control group (Fig. 3). While glucose ranged from 5.6 to $200 \mathrm{mM}$ increased GLUT2 expression in a concentration-dependent manner (Fig. 3). The expression of STR subunits (TAS1R2, TAS1R3) was significantly increased in the groups of 25,100 , and $200 \mathrm{mM}$ glucose in comparison to the group of $5.6 \mathrm{mM}$ glucose (Fig. 3).
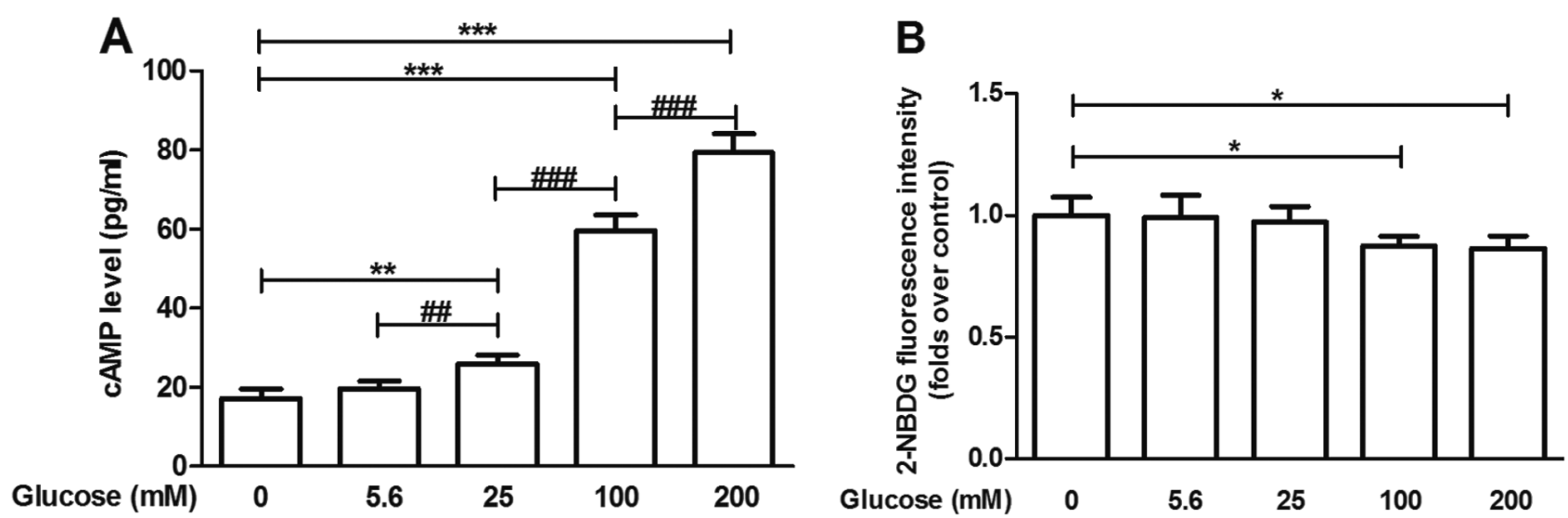

Figure 2. Effects of different concentrations of glucose on intracellular cAMP level and glucose uptake in STC-1 cells. STC-1 cells were incubated with different concentrations of glucose $(0,5.6,25,100$, and $200 \mathrm{mM})$ for $1 \mathrm{~h}$. A. Intracellular cAMP levels were measured by ELISA. ${ }^{* *} p<0.01,{ }^{* * *} p<0.001,{ }^{\# \#} p<0.01,{ }^{\# \# \#} p<0.001(n=6)$. B. 2 -NBDG fluorescence intensity incorporated into the cells was measured on a fluorescence microplate reader. All data were expressed as relative dimensionless number of glucose-free control group. ${ }^{*} p<0.05(n=6)$. 
A

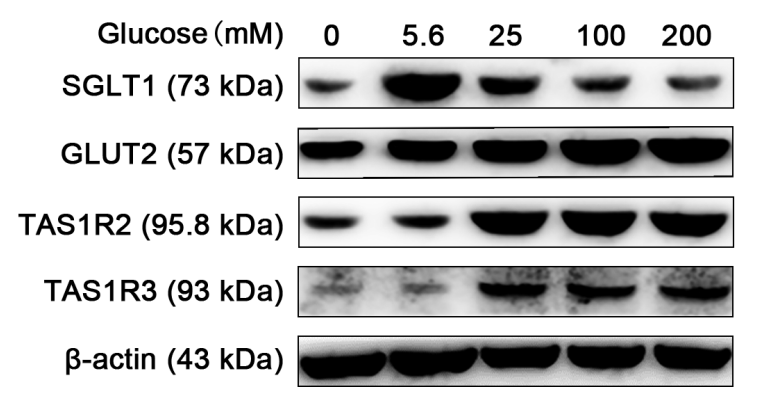

B

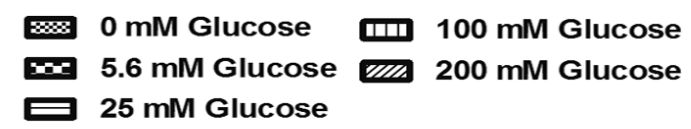

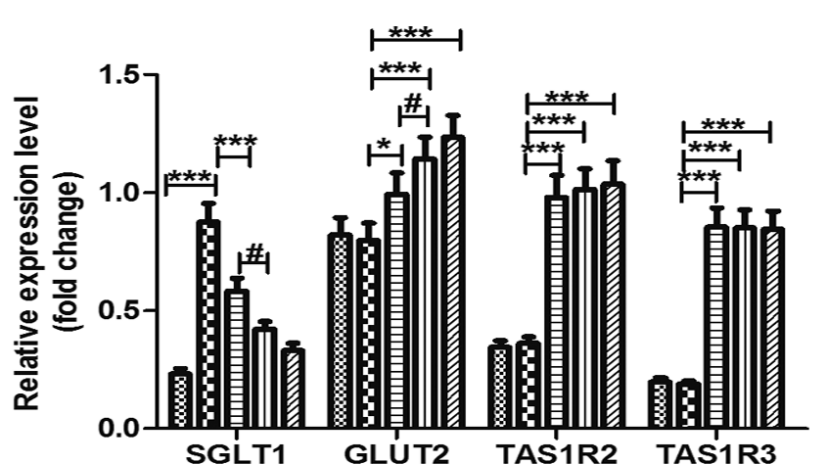

Figure 3. Effects of different concentrations of glucose on the protein level of SGLT1, GLUT2 and STR subunits in STC-1 cells. A. The protein expression of SGLT1, GLUT2 and STR subunits (TAS1R2 and TAS1R3) in STC-1 cells cultured in different concentrations of glucose $(0,5.6,25,100$, and $200 \mathrm{mM})$ for $1 \mathrm{~h}$ were measured by Western blot. $(n=3)$. B. The protein levels of SGLT1, GLUT2, TAS1R2, and TAS1R3 were analyzed by Image-J software. ${ }^{\star} p<0.05,{ }^{* *} p<0.001,{ }^{*} p<0.01(n=3)$.

Effects of pharmacological interference with SGLT1, GLUT2 or STRs on GLP-1 secretion and intracellular levels of cAMP and $\mathrm{Ca}^{2+}$

To further investigate the role of SGLT1, GLUT2 and STRs in GLP-1 secretion from STC-1 cells induced by different concentrations of glucose, we exposed STC-1 cells to different concentrations of glucose $(5.6,25,100$, and $200 \mathrm{mM})$ in the presence or absence of the SGLT1 inhibitor phloridzin, the GLUT2 inhibitor phloretin or the STR inhibitor lactisole for $1 \mathrm{~h}$ and evaluated GLP-1 secretion. GLP-1 secretion triggered by $5.6 \mathrm{mM}$ glucose was significantly decreased to approximately $85 \%$ in the presence of phloridzin (Fig. 4A). In the presence of phloridzin, GLP-1 secretion stimulated by high concentrations of glucose $(25,100$, and $200 \mathrm{mM})$ appeared to also have a tendency to decrease (Fig. 4A). In the presence of phloretin, GLP-1 secretion induced by glucose at 25,100 and $200 \mathrm{mM}$ was significantly reduced to $88 \%, 90 \%$, and $90 \%$, respectively (Fig. 4B). In the presence of lactisole phloretin, GLP-1 secretion induced by glucose at 25, 100 and $200 \mathrm{mM}$ was significantly reduced to $83 \%, 82 \%$, and $83 \%$, respectively (Fig. 4B). GLP-1 secretion induced by $5.6 \mathrm{mM}$ glucose in lactisole-treated STC-1 cells exhibited a tendency to decrease (Fig. 4C). We further examined the effects of phloridzin on intracellular levels of cAMP and $\mathrm{Ca}^{2+}$ under $5.6 \mathrm{mM}$ glucose condition. As shown in Fig. 4D, $5.6 \mathrm{mM}$ glucose-induced elevation of intracellular $\mathrm{Ca}^{2+}$ level was significantly decreased approximately $26 \%$ by phloridzin. No significant decrease in intracellular cAMP level was observed in the presence of phloridzin (Fig. 4E). The effects of phloretin or lactisole on intracellular levels of cAMP and $\mathrm{Ca}^{2+}$ under $25 \mathrm{mM}$ glucose condition were also examined. Following treatment with phloretin and lactisole, increases in intracellular $\mathrm{Ca}^{2+}$ induced by $25 \mathrm{mM}$ glucose was significantly decreased approximately $16 \%$ and $17 \%$, respectively (Fig. 4D). Under $25 \mathrm{mM}$ glucose condition, intracellular cAMP levels were significantly reduced approximately $27 \%$ by phloretin and approximately $42 \%$ by lactisole (Fig. $4 \mathrm{E}$ ).

Possible involvements of SGLT1, GLUT2 or STRs in GLP-1 secretion in response to 3-h low-glucose exposure

We incubated STC-1 cells with $5.6 \mathrm{mM}$ glucose for $3 \mathrm{~h}$ and then assessed GLP-1 secretion and intracellular levels of cAMP and $\mathrm{Ca}^{2+}$. Both GLP-1 secretion and intracellular $\mathrm{Ca}^{2+}$ level were significantly increased after $3 \mathrm{~h}$ compared to $1 \mathrm{~h}$ (Fig. 5A and C). 3-h exposure to $5.6 \mathrm{mM}$ glucose unaffected intracellular cAMP levels (Fig. 5B). Then, we exposed STC-1 cells to $5.6 \mathrm{mM}$ glucose in the presence or absence of the SGLT1 inhibitor phloridzin, the GLUT2 inhibitor phloretin or the STR inhibitor lactisole and then assessed GLP-1 secretion after 1-h and 3-h treatment. As shown in Fig. 5D, GLP-1 secretion induced 5.6 mM glucose for $3 \mathrm{~h}$ was impaired by inhibition of SGLT1 with phloridzin, which is consistent with the observations in 1-h treatment with phloridzin. Interestingly, inhibition of STRs with lactisole for $3 \mathrm{~h}$ significantly decreased GLP-1 secretion triggered by $5.6 \mathrm{mM}$ glucose (Fig. 5D). As expected, exposure to phloretin for $1 \mathrm{~h}$ or $3 \mathrm{~h}$ unaffected GLP-1 secretion in response to $5.6 \mathrm{mM}$ glucose stimulation (Fig. 5D).

\section{Discussion}

The development of new therapeutic strategies that aim to increase endogenous GLP-1 secretion makes the study of 
the GLP-1 stimulus-secretion pathways of growing interest. Using the STC-1 enteroendocrine cell model, the current study confirmed that GLP-1 secretion triggered by $5.6 \mathrm{mM}$ glucose was impaired by the SGLT1 inhibitor phloridzin. The observations were compatible with the results that this relatively low concentration of glucose upregulated SGLT1 expression. These results supported the idea that the involvement of SGLT1 in GLP-1 secretion induced by low concentrations of glucose. We also further established that glucose concentration $(25,100$, and $200 \mathrm{mM})$, similar to the postprandially luminal glucose concentration, stimulates GLP-1 secretion from STC-1 cells and this effect was attenuated by an addition of GLUT2 inhibitor phloretin or STR inhibitor lactisole. Furthermore, high glucose increased the protein levels of GLUT2 and STR subunits in comparison to low-glucose group. These results also indicated the im-

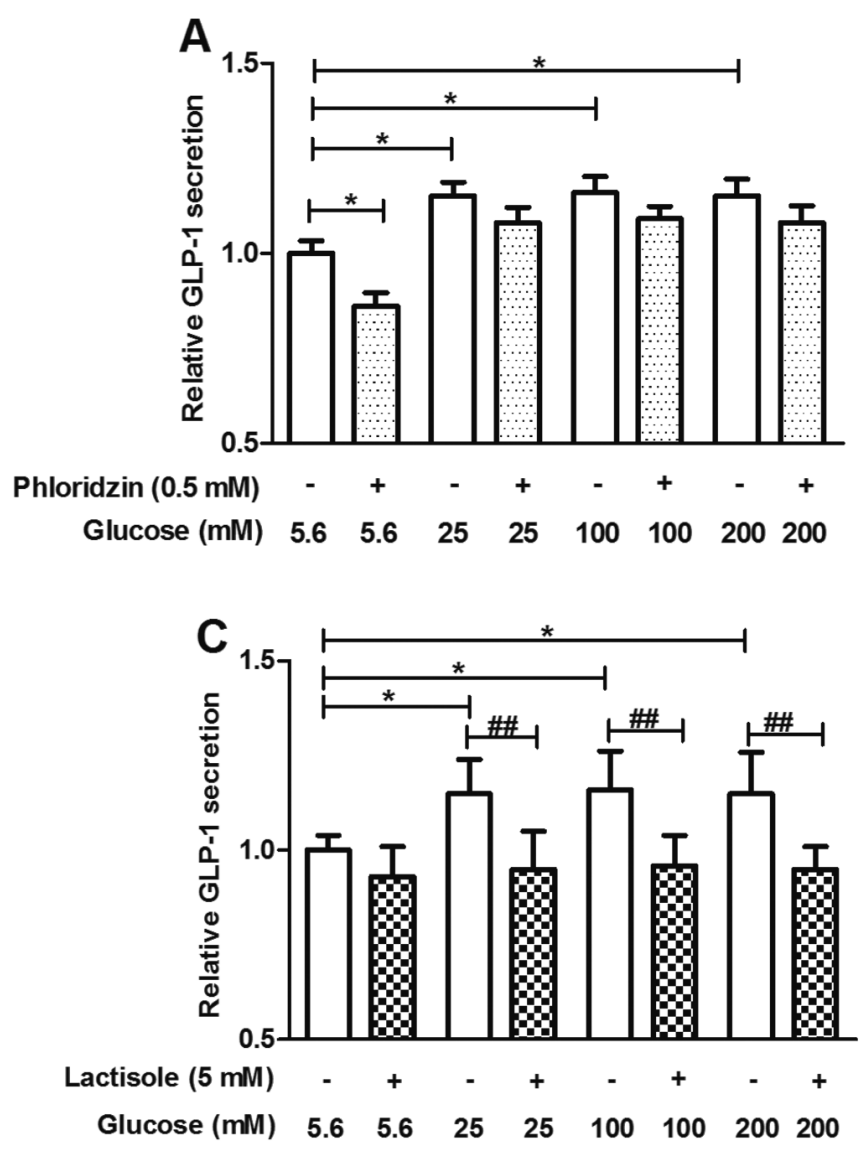

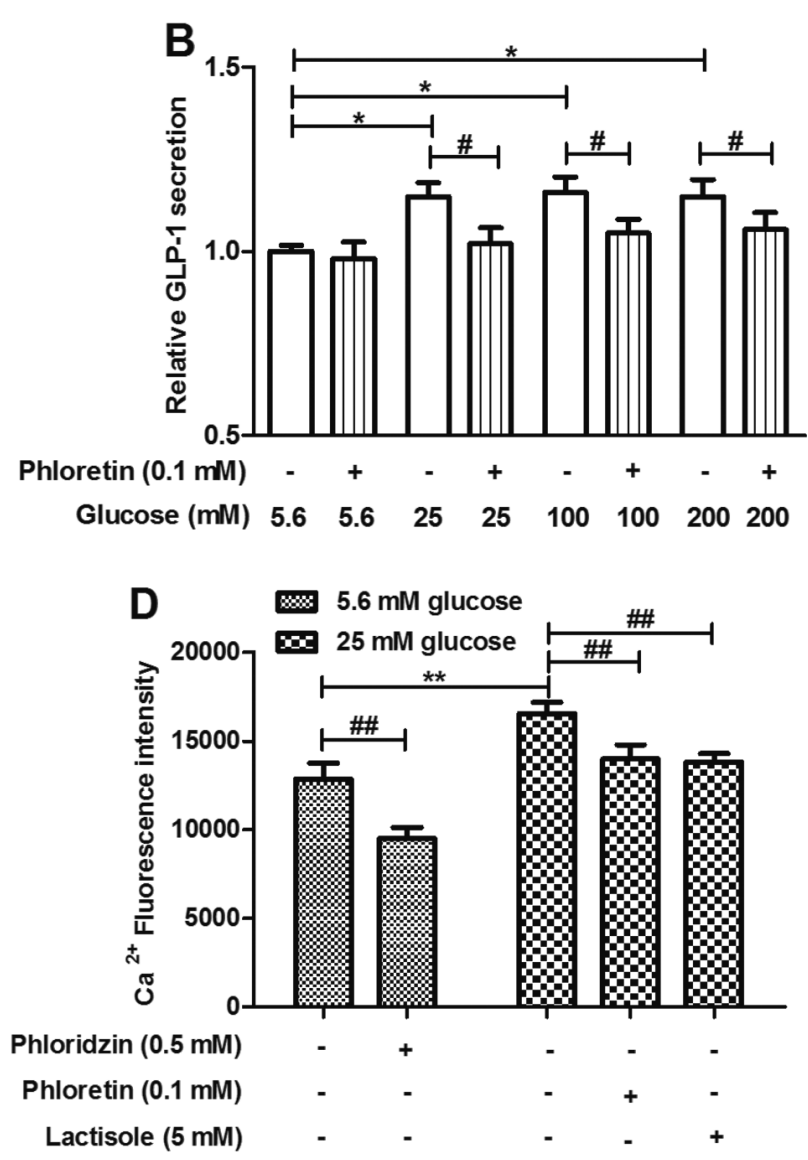

Figure 4. Effects of pharmacological interference with SGLT1, GLUT2 or STRs on GLP-1 secretion and intracellular levels of cAMP and $\mathrm{Ca}^{2+}$ in STC-1 cells. STC-1 cells were incubated for $1 \mathrm{~h}$ with different concentrations of glucose $(5.6,25,100$, and $200 \mathrm{mM}$ ) in the absence and presence of the SGLT1 inhibitor phloridzin $(0.5 \mathrm{mM}$; A), the GLUT2 inhibitor phloretin $(0.1 \mathrm{mM} ; \mathbf{B})$ or the STR inhibitor lactisole ( $5 \mathrm{mM}$; C), and GLP-1 concentration in the supernatant was measured by ELISA. STC- 1 cells were incubated for $1 \mathrm{~h}$ in the absence and presence of phloridzin $(0.5 \mathrm{mM})$ under $5.6 \mathrm{mM}$ glucose condition, and phloretin $(0.1 \mathrm{mM})$ and lactisole ( $5 \mathrm{mM}$ ) under $25 \mathrm{mM}$ glucose condition; and intracellular levels of $\mathrm{Ca}^{2+}(\mathbf{D})$ and cAMP (E) in STC-1 cells were measured. All data were expressed as relative dimensionless number of $5.6 \mathrm{mM}$ glucose group. ${ }^{*} p<0.05,{ }^{* *} p<0.01,{ }^{* * *} p<0.001,{ }^{\#} p<0.05,{ }^{\# \#} p<$ $0.01,{ }^{\# \# \#} p<0.001(n=6)$. 
portance of STRs and GLUT2 in GLP-1 secretion triggered by high glucose.

It has reported that GLUTag and primary murine L-cells express both SGLT1 and GLUT2 transporters (Frank et al. 2008). Our results also presented evidence for the protein expression of SGLT1 and GLUT2 on mouse enteroendocrine cell line STC-1. It is well known that SGLT1 and GLUT2 are the two types of glucose transporters, active and facilitative, respectively. Recently, using the pharmacological interference with GLUT2, studies have demonstrated that GLUT2 largely dominate intracellular glucose concentrations in GLUTag cells and primary intestinal cultures (Parker et al. 2012). Our results showed that GLUT2, but not SGLT1, was gradually increased when glucose concentration was raised from 5.6 to $200 \mathrm{mM}$, which is in agreement with the previous report (Kellett and Helliwell 2000). These results observed in
STC- 1 cells may suggest that increased GLUT2 expression led to elevation of intracellular glucose concentrations. Thus, the decreased 2-NBDG uptake ability could be observed in STC-1 cells after exposure to a high concentration of glucose. Indeed, Teusink et al. (1998) observed that when the intracellular glucose concentration is high, the glucose influx would be reduced. In addition, since Sun et al. (2017) reported that $300 \mathrm{mM}$ mannitol failed to induce GLP-1 secretion, we believe that the decreased glucose uptake is not secondary to osmotic stress.

The relative roles of SGLT1 and GLUT2 in glucoseinduced GLP-1 secretion were investigated in seminal studies using pharmacological and genetic interference with SGLT1 and GLUT2 (Cani et al. 2007; Gorboulev et al. 2012; Parker et al. 2012), suggesting some SGLT1 are required for glucose-induced GLP-1 secretion. Electrogenic SGLT1
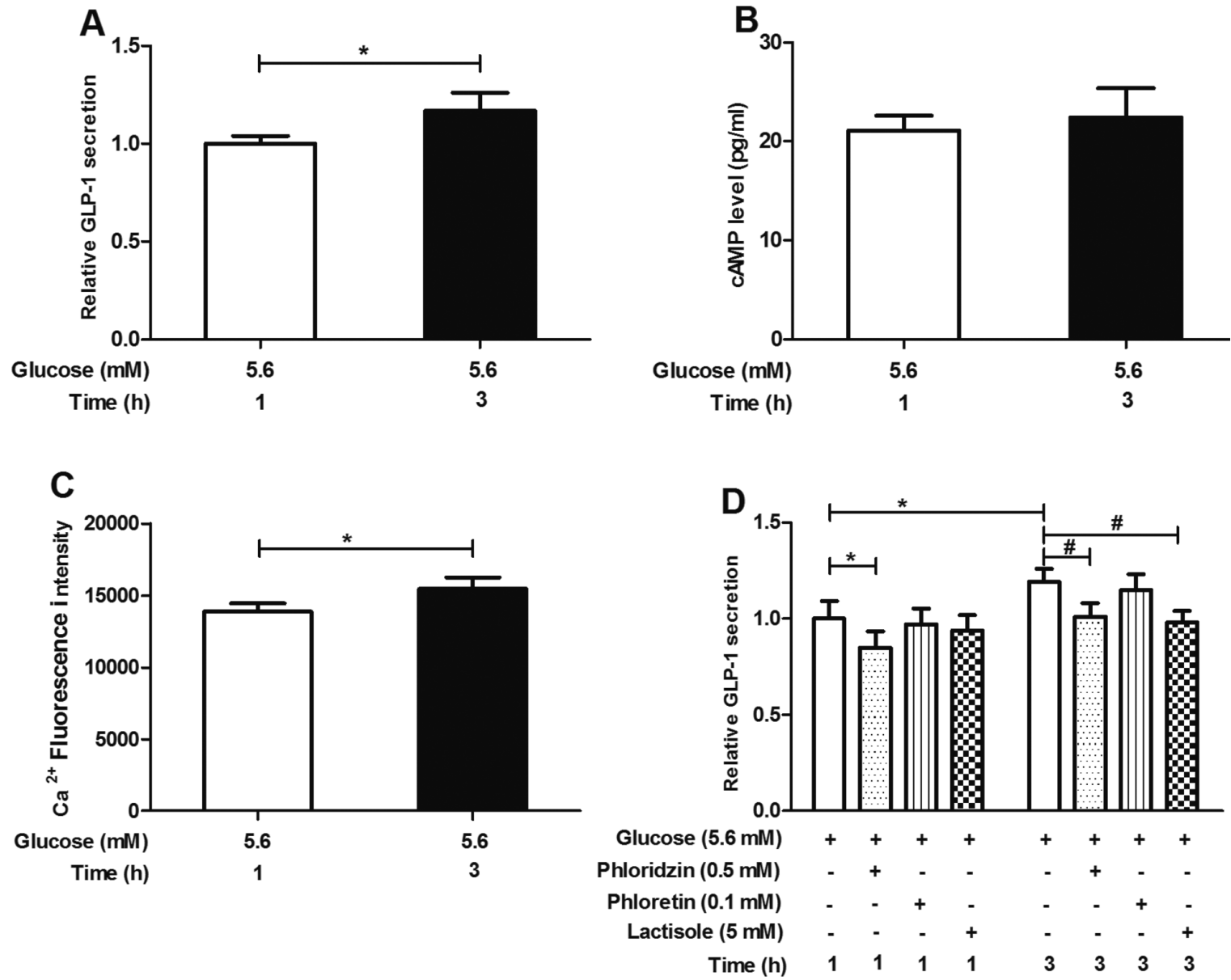

Figure 5. Possible involvements of SGLT1, GLUT2 or STRs in GLP-1 secretion in response to 3-h low-glucose exposure. STC-1 cells were incubated at $5.6 \mathrm{mM}$ glucose in the presence or absence of the SGLT1 inhibitor phloridzin, the GLUT2 inhibitor phloretin or the STR inhibitor lactisole for $1 \mathrm{~h}$ or $3 \mathrm{~h}$. (A, D) The GLP-1 concentration in the supernatant was measured by ELISA. The data were expressed as relative dimensionless number of 1 - $\mathrm{h}$ group. B. Intracellular cAMP levels were measured by ELISA. C. The $\mathrm{Ca}^{2+}$ concentrations in STC- 1 cells were measured at the 488/525-530 nm fluorescence ratio in the cells loaded with fluo-3/AM. ${ }^{*} p<0.05,{ }^{\#} p<0.05$ ( $n=6$ ). 
triggers electrical activity and the subsequent elevation of intracellular $\mathrm{Ca}^{2+}$, which in turn evokes GLP-1 secretion especially in the presence of low concentrations of glucose (Gribble et al. 2003). Our results also identified the pivotal roles of electrogenic SGLT1 in GLP-1 secretion from STC-1 cells induced by low concentrations of glucose: 1) $5.6 \mathrm{mM}$ glucose increased GLP-1 secretion and intracellular $\mathrm{Ca}^{2+}$ level as well as SGLT1 protein expression; 2) GLP-1 secretion and intracellular $\mathrm{Ca}^{2+}$ concentration under $5.6 \mathrm{mM}$ glucose condition was decreased by the SGLT1 inhibitor phloridzin. The role of GLUT2 for glucose-induced GLP-1 secretion is mediated by an amplifying pathway at a given $\mathrm{Ca}^{2+}$ level and this amplifying pathway is also dependent on the SGLT1mediated triggering pathway (Tagliavini and Pedersen 2017). In the current study, as a result of upregulation of GLUT2 expression, cAMP level is increased with glucose-dependent manner. Importantly, inhibition of GLUT2 decreased GLP-1 secretion and intracellular levels of $\mathrm{Ca}^{2+}$ and cAMP under high-glucose conditions. These results suggested the involvement of GLUT2 in GLP-1 secretion triggered by high concentrations of glucose, associated with cAMP and $\mathrm{Ca}^{2+}$ signaling system. While elevation of intracellular levels of $\mathrm{Ca}^{2+}$ and cAMP secondary to GLUT2-mediated glucose transport under high glucose conditions can increase GLP-1 secretion, but the increment is limited, which could explain the results that glucose at 100 and $200 \mathrm{mM}$ did not further augment intracellular $\mathrm{Ca}^{2+}$ and GLP-1 secretion.

STR activation mobilizes $\mathrm{Ca}^{2+}$ from intracellular stores by the activation of phospholipase $\mathrm{C}$ and inositol triphosphate (Roper 2007). The increase in intracellular $\mathrm{Ca}^{2+}$ opens the Transient Receptor Potential Cation Channel Subfamily M Member 5, leading to $\mathrm{Na}^{+}$influx, depolarization of the cell, and eventually GLP-1 secretion (Liu and Liman 2003). STR activation also activates adenylate cyclase and thereby leads to the formation of cAMP (Roper 2007). In MIN-6 beta cells, activation of STRs also facilitates the metabolic pathway in mitochondria and augments ATP production (Nakagawa et al. 2014). Glucose is a bona fide ligand for STRs and glucose-induced GLP-1 secretion is inhibited using pharmacological and genetic interference with STRs (Jang et al. 2007). Lactisole is usually used to assess the function and physiological role of the STRs in human. Some recent reports suggest that lactisole may be useful in assessing the role of STRs in rodents (Hamano et al. 2015). In the present study, co-administration of the STR inhibitor lactisole reduced GLP-1 secretion triggered by high glucose, which provides a useful pharmacological tool to assess the function of STRs in STC-1 cells. Moreover, high glucose increased STR subunits expression. These results also support the high-glucoseinduced elevation of the intracellular cAMP and $\mathrm{Ca}^{2+}$ levels observed in our study. Taken together, STR signaling is also involved in GLP-1 secretion stimulated by high glucose. Interestingly, while STC-1 cells upon 1-h lactisole exposure exhibited a tendency to decrease in GLP-1 secretion triggered by $5.6 \mathrm{mM}$ glucose, 3 -h lactisole treatment obviously decreased GLP-1 secretion induced by $5.6 \mathrm{mM}$ glucose. It may account for the result that 3-h exposure to $5.6 \mathrm{mM}$ glucose-induced the sustained increase in GLP-1 secretion and intracellular $\mathrm{Ca}^{2+}$ levels. These results indicate the possible involvement of STRs in GLP-1 secretion induced by low glucose under certain conditions, but it requires being further investigated.

The existence of different physiological states should be considered when we study molecular function, in addition to the structure. In the current study, we pay attention to the role of glucose sensors, including SGLT1, GLUT2, and STR, in GLP-1 secretion under low-glucose and high-glucose conditions. Our data from STC-1 cells show that GLP-1 secretion is predominantly controlled by SLGT1 whereas GLUT2 and STR are involved when glucose concentrations in the medium are high. On the basis of the study and the above-mentioned reports, it was concluded that SGLT1 signals for glucose-stimulated GLP-1 secretion act in synergy with STR signaling and GLUT2 signaling, but it requires being further investigated.

Acknowledgments. This study was funded by Suzhou Introduction Program for Clinical Medical Expert Team (grant number SZYJTD201718), Suzhou Science and Technology Department (grant number SYSD2017191), Suzhou TCM Hospital Affiliated to Nanjing University of Chinese Medicine (grant number YQN2016002), and the National Natural Science Foundation of China (grant number 81973740).

\section{References}

Benaiges D, Goday A, Ramon JM, Hernandez E, Pera M, Cano JF (2011): Laparoscopic sleeve gastrectomy and laparoscopic gastric bypass are equally effective for reduction of cardiovascular risk in severely obese patients at one year of follow-up. Surg. Obes. Relat. Dis. 7, 575-580 https://doi.org/10.1016/j.soard.2011.03.002

Cani PD, Holst JJ, Drucker DJ, Delzenne NM, Thorens B, Burcelin R, Knauf C (2007): GLUT2 and the incretin receptors are involved in glucose-induced incretin secretion. Mol. Cell Endocrinol. 276, 18-23

https://doi.org/10.1016/j.mce.2007.06.003

Doyle ME, Egan JM (2007): Mechanisms of action of glucagonlike peptide 1 in the pancreas. Pharmacol. Ther. 113, 546-493 https://doi.org/10.1016/j.pharmthera.2006.11.007

Drucker DJ, Nauck MA (2006): The incretin system: glucagon-like peptide- 1 receptor agonists and dipeptidyl peptidase- 4 inhibitors in type 2 diabetes. Lancet 368, 1696-1705 https://doi.org/10.1016/S0140-6736(06)69705-5

Frank R, Habib AM, Gwen T, Parker HE, Rogers GJ, Gribble FM (2008): Glucose sensing in L cells: a primary cell study. Cell Metab. 8, 532-539 https://doi.org/10.1016/j.cmet.2008.11.002 
Gorboulev V, Schürmann A, Vallon V, Kipp H, Jaschke A, Klessen D, Friedrich A, Scherneck S, Rieg T, Cunard R, et al. (2012): $\mathrm{Na}(+)$-D-glucose cotransporter SGLT1 is pivotal for intestinal glucose absorption and glucose-dependent incretin secretion. Diabetes 61, 187-196 https://doi.org/10.2337/db11-1029

Gribble FM, Williams L, Simpson AK, Reimann F (2003): A novel glucose-sensing mechanism contributing to glucagon-like peptide-1 secretion from the GLUTag cell line. Diabetes 52, 1147-1154 https://doi.org/10.2337/diabetes.52.5.1147

Hamano K, Nakagawa Y, Ohtsu Y, Li L, Medina J, Tanaka Y, Masuda K, Komatsu M, Kojima I (2016): Lactisole inhibits the glucosesensing receptor T1R3 expressed in mouse pancreatic $\beta$-cells. J. Endocrinol. 226, 57-66 https://doi.org/10.1530/JOE-15-0102

Holst JJ (2007): The physiology of glucagon-like peptide 1. Physiol. Rev. 87, 1409-1439 https://doi.org/10.1152/physrev.00034.2006

Jang HJ, Kokrashvili Z, Theodorakis MJ, Carlson OD, Kim BJ, Zhou J, Kim HH, Xu X, Chan SL, Juhaszova M, et al. (2007): Gut-expressed gustducin and taste receptors regulate secretion of glucagon-like peptide-1. Proc. Natl. Acad. Sci. USA 104, 15069-15074 https://doi.org/10.1073/pnas.0706890104

Kellett GL, Brot-Laroche E (2005): Apical GLUT2: a major pathway of intestinal sugar absorption. Diabetes 54, 3056-3062 https://doi.org/10.2337/diabetes.54.10.3056

Kellett GL, Helliwell PA (2000): The diffusive component of intestinal glucose absorption is mediated by the glucose-induced recruitment of GLUT2 to the brush-border membrane. Biochem. J. 350, 155-162 https://doi.org/10.1042/bj3500155

Kim W, Egan JM (2008): The role of incretins in glucose homeostasis and diabetes treatment. Pharmacol. Rev. 60, 470-512 https://doi.org/10.1124/pr.108.000604

Kokrashvili Z, Mosinger B, Margolskee RF (2009): Taste signaling elements expressed in gut enteroendocrine cells regulate nutrient-responsive secretion of gut hormones. Am. J. Clin. Nutr. 90, 822S-825S https://doi.org/10.3945/ajcn.2009.27462T

Kuhre RE, Frost CR, Svendsen B, Holst JJ (2015): Molecular mechanisms of glucose-stimulated GLP-1 secretion from perfused rat small intestine. Diabetes 64, 370-382 https://doi.org/10.2337/db14-0807

Liu D, Liman ER (2003): Intracellular Ca2+ and the phospholipid PIP2 regulate the taste transduction ion channel TRPM5. Proc. Natl. Acad. Sci. USA 100, 15160-15165 https://doi.org/10.1073/pnas.2334159100

Nakagawa Y, Ohtsu Y, Nagasawa M, Shibata H, Kojima I (2014): Glucose promotes its own metabolism by acting on the cell-surface glucose-sensing receptor T1R3. Endocr. J. 61, $119-131$ https://doi.org/10.1507/endocrj.EJ13-0431

Parker HE, Adriaenssens A, Rogers G, Richards P, Koepsell H, Reimann F, Gribble FM (2012): Predominant role of active versus facilitative glucose transport for glucagon-like peptide-1 secretion. Diabetologia 55, 2445-2455 https://doi.org/10.1007/s00125-012-2585-2

Roper SD (2007): Signal transduction and information processing in mammalian taste buds. Pflugers Arch. 454, 759-776 https://doi.org/10.1007/s00424-007-0247-x

Shuster LT, Go VL, Rizza RA, O'Brien PC, Service FJ (1988): Incretin effect due to increased secretion and decreased clearance of insulin in normal humans. Diabetes 37, 200-203 https://doi.org/10.2337/diab.37.2.200

Simpson AK, Ward PS, Wong KY, Collord GJ, Habib AM, Reimann F, Gribble FM (2007): Cyclic AMP triggers glucagon-like peptide-1 secretion from the GLUTag enteroendocrine cell line. Diabetologia 50, 2181-2189 https://doi.org/10.1007/s00125-007-0750-9

Sun EW, de Fontgalland D, Rabbitt P, Hollington P, Sposato L, Due SL, Wattchow DA, Rayner CK, Deane AM, Young RL, Keating DJ (2017): Mechanisms controlling glucose-induced Glp-1 secretion in human small intestine. Diabetes 66, 2144-2149 https://doi.org/10.2337/db17-0058

Tagliavini A, Pedersen MG (2017): Spatiotemporal modeling of triggering and amplifying pathways in GLP-1 secreting intestinal L cells. Biophys. J. 112, 162-171 https://doi.org/10.1016/j.bpj.2016.11.3199

Teusink B, Diderich JA, Westerhoff HV, van Dam K, Walsh MC (1998): Intracellular glucose concentration in derepressed yeast cells consuming glucose is high enough to reduce the glucose transport rate by $50 \%$. J. Bacteriol. 180, 556-562

Wang F, Zhou L, Song X, Liang G, Xu H, Zhang L, Jiang G (2017): Acute reduction of incretin effect and glucose intolerance in rats by single intragastric administration of 3-deoxyglucosone. Exp. Clin. Endocrinol. Diabetes 125, 4-11 https://doi.org/10.1055/s-0042-111684

Xu Z, Wang W, Nian X, Song G, Zhang X, Xiao H, Zhu X (2016): Dosedependent effect of glucose on GLP-1 secretion involves sweet taste receptor in isolated perfused rat ileum. Endocr. J. 63, 1141 https://doi.org/10.1507/endocrj.EJ16-0390

Received: April 26, 2019

Final version accepted: September 14, 2019 